Jurnal PRIMATIKA, Volume 8, Nomor 2, Desember 2019

\title{
MENGHITUNG KAPASITAS RUNWAY MENGGUNAKAN PETRI NET DAN ALJABAR MAX-PLUS
}

\author{
Petrus Fendiyanto \\ Dosen Pendidikan Matematika FKIP Universitas Mulawarman \\ Email:petrus@fkip.unmul.ac.id
}

\begin{abstract}
ABSTRAK
Bandara Internasional Juanda merupakan bandara tersibuk kedua di Indonesia setelah Bandara Internasional Soekarno-Hatta, yang tiap tahun jumlah penumpangnya mengalami peningkatan. Begitu juga dari sisi pergerakan pesawat juga mengalami peningkatan dari tahun ke tahun. Yang dimaksud pergerakan pesawat adalah total pesawat yang mendarat dan yang lepas landas di runway. Menurut Operation Junior Manager Perum LPPNPI (Lembaga Penyelenggara Pelayanan Navigasi Penerbangan Indonesia), kapasitas maksimal runway Bandara Juanda adalah 28 pergerakan peasawat take offllanding per jam. Namun yang terjadi belakangan dapat mencapai 34 pergerakan pesawat per jam. Penelitian ini dimaksudkan bagaimana menentukan kapasitas runway sebagai batas maksimum banyaknya pergerakan pesawat di runway dalam tiap jamnya dengan menggunakan petri net dan aljabar max-plus sebagai alat pemodelannya. Dalam mengerjakan penelitian ini, dibuat model petri net dari alur pergerakan pesawat yang dimulai dari saat pesawat bergerak menuju exit taxiway kemudian menuju ke runway dan selanjutnya meninggalkan bandara (take off) dan proses landing dimulai dari posisi pesawat di approach (siap landing), dan selanjutnya bergerak menuju ke runway. Kemudian membuat model aljabar max-plus dari model petri net dan terakhir menganalisis sifat keperiodikan sistem tersebut. Dari hasil simulasi model aljabar max-plus diperoleh bahwa dalam 60 menit pertama, sebanyak 15 pesawat yang take off dan 15 pesawat yang landing, artinya kapasitas runway Bandara Internasional Juanda adalah 30 pesawat (take off/landing) dalam tiap jamnya.
\end{abstract}

Kata kunci: Aljabar Max-Plus, Kapasitas Runway, Petri Net

\begin{abstract}
Juanda International Airport is the second busiest airport in Indonesia after SoekarnoHatta International Airport. Every year the number of passengers has increased. The plane movement is also increased. The plane movement consists of plane landing and taking off on the runway. According to Junior Manager Institutions Organizers of Air Navigation Services Indonesia, Juanda Airport runway maximum capacity is 28 planes movement. In reality, it reaches 34 planes movement per hour. This research aimed to determine the capacity of the runway as the maximum number of plane movements on the runway in every hour by using petri nets and Max-Plus Algebra as a modelling tool. In doing this research, we created a model of petri nets of plane movement routes. Petri nets are used to model the take off and landing processes. In the take off process, initially the plane is in the exit taxiway. Then the plane moves to runway. Finally, the plane leaves the airport. In the
\end{abstract}


landing process, initially the plane is in the approach. In addition, the plane moves to runway. Finally, the plane goes to exit taxiway. Then, we make Max-Plus Algebra models from petri nets models that have been obtained, and analyse the nature of the system's periodicity. From the result of the simulation model of Max-Plus Algebra, we obtained that in the first 60 minutes, as many as 15 planes take off and 15 planes are landing, meaning Juanda International Airport runway capacity is 30 planes (take off/landing) in every hour.

Keywords: Max-Plus Algebra, Petri Nets, Runway Capacity

\section{PENDAHULUAN}

Bandara Juanda merupakan bandara udara internasional yang memegang peranan penting dalam pertumbuhan ekonomi serta merupakan salah satu pintu gerbang menuju Provinsi Jawa Timur, yang merupakan salah satu provinsi terbesar di Indonesia. Bandara Juanda yang dikelola oleh PT Angkasa Pura I ini berada di Kecamatan Sedati Kabupaten Sidoarjo, 20 km sebelah selatan kota Surabaya. Bandara Juanda pertama kali didirikan pada tahun 1969 dan mulai beroperasi pada tahun 1982 pada lahan seluas $396 \mathrm{Ha}$, merupakan klasifikasi bandara 1A yang melayani perjalanan rute domestik dan mancanegara. Bandara ini merupakan bandara tersibuk kedua di Indonesia setelah Bandara Soekarno-Hatta, yang tiap tahun jumlah penumpangnya mengalami peningkatan.

Berdasarkan harian beritrans.com, menyebutkan bahwa rute penerbangan Jakarta-Surabaya merupakan terpadat di Indonesia. Selain itu, harian tribunnews.com menyebutkan bahwa jumlah penumpang pesawat terbang di Indonesia mengalami peningkatan setiap tahunnya sehingga jumlah pesawat di semua bandara, termasuk Bandara Juanda juga meningkat. Begitu juga dari sisi pergerakan pesawat, mengalami peningkatan dari tahun ke tahun meskipun tahun 2014 mengalami penu- runan 3\% dikarenakan adanya insiden jatuhnya pesawat maskapai airasia tujuan Surabaya-Singapura yang terjadi pada akhir tahun, dan pada tahun 2015 jumlah pergerakan pesawat mencapai 137.051 (penerbangan domestik dan internasional) atau naik sekitar $0.63 \%$ dari tahun sebelumnya (PT. Angkasa Pura I (Persero) Bandara Udara Internasional Juanda). Yang dimaksud dengan pergerakan pesawat adalah total pesawat yang mendarat dan yang lepas landas di runway.

Menurut Operation Junior Manager Perum LPPNPI (Lembaga Penyelengara Pelayanan Navigasi Penerbangan Indonesia), kapasitas maksimal runway Bandara Juanda adalah 28 pergerakan pesawat take off/landing per jam. Namun yang terjadi belakangan dapat mencapai 34 pergerakan pesawat per jam. Jika dilihat dari spesifikasi bandara, Bandara Internasional Juanda hanya memiliki satu buah runway yang digunakan untuk landing maupun take off. Sebagai pembandingnya, Bandara Internasional Soekarno-Hatta memiliki jumlah runway lebih banyak yaitu sebanyak dua buah. Mengingat jumlah pergerakan yang terjadi di Bandara Juanda memiliki kepadatan yang tinggi selayaknya Bandara Soekarno-Hatta, tentunya ini menjadi hal yang perlu diperhatikan lebih. Dari beberapa penjelasan di atas, pada penelitian 
ini dimaksudkan bagaimana menentukan kapasitas runway sebagai batas maksimum banyaknya pergerakan pesawat di runway dalam tiap jamnya dengan menggunakan model petri net dan aljabar max-plus sebagai alat pemodelannya.

\section{TINJAUAN PUSTAKA}

\section{A. Petri Net}

Petri net dapat dituliskan sebagai 4tuple $(P, T, A, w)$ dengan

$P=\left\{p_{1}, p_{2}, \cdots, p_{n}\right\}$ adalah himpunan berhingga place,

$T=\left\{t_{1}, t_{2}, \cdots, t_{m}\right\}$ adalah himpunan berhingga transisi,

$A \subseteq(P \times T) \cup(T \times P)$ adalah himpunan dari garis berarah (arcs),

$w: A \rightarrow\{1,2,3, \cdots\}$ adalah fungsi bobot pada $\operatorname{arcs}$.

Transisi pada petri net merupakan representasi dari pergerakan event pada Sistem Event Diskrit (SED), sedangkan place merepresentasikan kondisi agar event pada sistem dapat terjadi. Dalam hal ini, diperlukan alat sebagai penanda apakah kondisi tersebut dapat terpenuhi atau tidak, dengan cara memberikan token yaitu suatu tanda yang diletakan pada place. Dalam model petri net, token direpresentasikan dengan dot, dan jika jumlah token banyak maka dituliskan dengan angka.

Dalam notasi matematika petri net bertanda ditulis sebagai 5-tuple $(P, T, A, w, x)$ dengan $(P, T, A, w)$ adalah petri net dan $x$ adalah fungsi $x: P \rightarrow \mathbb{N}=$ $\{1,2, \cdots\}$. Penanda (marking) $x$ dalam petri net dinyatakan dengan vektor kolom yang elemen-elemennya berkaitan dengan $x$, yaitu bilangan bulat tak negatif (banyaknya token dalam suatu place), $x=$ $\left[x\left(p_{1}\right), x\left(p_{2}\right), \cdots, x\left(p_{m}\right)\right]^{\prime}$. Elemen ke- $i$ pada vektor ini merupakan banyaknya token pada place $p_{i}$, dengan $x\left(p_{i}\right) \in$ $\{0,1,2,3 \cdots\}$.

Suatu transisi $t_{j} \in T$ dalam sebuah petri net dikatakan kondisi terpenuhi (enabled) jika

$$
x\left(p_{i}\right) \geq w\left(p_{i}, t_{j}\right) \text { untuk setiap } p_{i} \in I\left(t_{j}\right)
$$

dengan $I\left(t_{j}\right)$ merupakan himpunan place input dari transisi $t_{j}$.

Mekanisme perubahan keadaan pada petri net ditandai dengan perpindahan token-token pada petri net tersebut sehingga mengubah keadaan petri net. Secara umum, sebuah transisi pada petri net yang enabled, diistilahkan dengan dapat di-fire (firing diartikan dengan transisi di-fire). Fungsi perubahan keadaan petri net ini merupakan perubahan keadaan petri net sebelum dan sesudah suatu transisi di-fire.

\section{B. Aljabar Max-Plus}

Aljabar max-plus adalah suatu struktur aljabar yang terdiri dari $\mathbb{R}_{\epsilon}$ dengan $\mathbb{R}_{\epsilon}=\mathbb{R} \cup\{\epsilon\}$ dan $\epsilon=-\infty$ dengan dua operator biner yaitu Operator Max $(\oplus$ "dibaca: oplus") dan Operator Plus $(\otimes$ "dibaca: otimes"), yang didefinisikan sebagai berikut, $\forall x, y \in \mathbb{R}_{\epsilon}$ $x \oplus y=\max \{x, y\}$ dan $x \otimes y=x+y$

Diketahui bahwa $\left(\mathbb{R}_{\epsilon}, \oplus, \otimes\right)$ meru-pakan semiring komutatif dengan elemen netral $\epsilon$ dan elemen satuan $e(e=0)$.

Himpunan matriks berukuran $m \times n$ dalam aljabar max-plus dinotasikan dengan $\mathbb{R}_{\epsilon}^{m \times n}$. Untuk $n \in \mathbb{N}$ dan $n \neq 0$, didefinisikan $\underline{n}=\{1,2, \cdots, n\}$. Elemen matriks $A \in \mathbb{R}_{\epsilon}^{m \times n}$ pada baris ke- $i$ dan pada kolom ke- $j$ dinotasikan dengan $a_{i j}$, untuk $i \in \underline{m}$ dan $j \in \underline{n}$. Dalam hal ini matriks $A$ mempunyai $m$ baris dan $n$ kolom dan dapat ditulis dalam bentuk persamaan 


$$
A=\left[\begin{array}{cccc}
a_{11} & a_{12} & \cdots & a_{1 n} \\
a_{21} & a_{22} & \cdots & a_{2 n} \\
\vdots & \vdots & \ddots & \vdots \\
a_{m 1} & a_{m 2} & \cdots & a_{m n}
\end{array}\right]
$$

Nilai eigen dan vektor eigen merupakan nilai karakteristik dan vektor karakteristik yang bersesuaian dengan matriks persegi $A$ berukuran $m \times m$, yang didefiniskan sebagai berikut, misalkan $A \in \mathbb{R}_{\epsilon}^{m \times m}$ merupakan matriks persegi. Jika $\lambda \in \mathbb{R}$ adalah skalar dan $\boldsymbol{v} \in \mathbb{R}_{\epsilon}^{m}$ adalah vektor yang seidaknya memuat satu elemen tak nol $(\epsilon)$ sedemikian sehingga

$$
A \otimes v=\lambda \otimes v
$$

dengan nilai eigen $\lambda$.

Dalam (Heidergott, 2006) menjelaskan bahwa jika $x_{i}(k)$ dianggap sebagai variabel keadaan yang menunjukan waktu transisi $t_{i}$ difire saat ke- $k$, dan

$$
x(k)=\left[x_{1}(k), x_{2}(k), \cdots, x_{|T|}(k)\right]^{\prime}
$$

maka memenuhi kaedah persamaan linear dalam aljabar max-plus (persamaan (implicit) relasi rekurensi).

$$
x(k)=\bigoplus A_{m} \otimes x(k-m), k \geq 0
$$

Persamaan relasi rekurensi di atas merupakan relasi rekurensi orde- $M$. Persamaan tersebut dapat ditransformasikan ke dalam relasi rekurensi orde-1 seperti berikut ini

$$
x(k+1)=A \otimes x(k), k \geq 0
$$

$A_{0}$ pada persamaan di atas mempunyai bobot sirkuit rata-rata kurang dari atau sama dengan $e$ atau tidak mempunyai sirkuit sama sekali, sehingga

$$
A_{0}^{*}=\bigoplus A_{0}^{\otimes i}
$$

dengan sedikit manipulasi aljabar yaitu dengan memisalkan bahwa,

$$
b(k)=\bigoplus A_{m} \otimes x(k-m)
$$

maka persamaannya dapat dikontruksi ulang menjadi persamaan

$$
x(k)=A_{0} \otimes x(k) \oplus b(k)
$$

sehingga persamaan dapat ditulis sebagai

$$
x(k)=A_{0}^{*} \otimes b(k)
$$

atau secara eksplisit

$$
\begin{gathered}
x(k)=A_{0}^{*} \otimes A_{1} \otimes x(k-1) \oplus \cdots \oplus \\
A_{0}^{*} \otimes A_{M} \otimes x(k-M)
\end{gathered}
$$

dengan mentransformasikan ke dalam bentuk persamaan relasi rekurensi orde-1, yaitu dengan terlebih dahulu memisalkan $\tilde{x}(k)=\left[x^{\prime}(k-1), x^{\prime}(k-2), \cdots, x^{\prime}(k-\right.$ $M)^{\prime}$

dan

$\left[\begin{array}{cccc}A_{0}^{*} \otimes A_{1} & A_{0}^{*} \otimes A_{2} & \cdots & A_{0}^{*} \otimes A_{M} \\ E & \epsilon & \cdots & \epsilon \\ \epsilon & E & \cdots & \epsilon \\ \vdots & \vdots & \ddots & \vdots \\ \epsilon & \epsilon & E & \epsilon\end{array}\right]$ sehingga didapatkan persamaan terakhir dalam bentuk

$$
\tilde{x}(k+1)=\tilde{A}(k) \otimes \tilde{x}(k), k \geq 0
$$

\section{HASIL PENELITIAN DAN PEMBA- HASAN}

\section{A. Model Petri Net Pergerakan Pesa- wat di Runway}

Pergerakan pesawat yang dimodelkan ini, dimulai dari saat pesawat bergerak menuju ke exit taxiway kemudian menuju ke runway dan selanjutnya pesawat meninggalkan bandara (take off) dan proses landing dimulai dari posisi pesawat di approach (siap landing), dan selanjutnya pesawat bergerak menuju ke runway seperti yang tampak pada gambar 1 .

\section{Keterangan:}

R10: Runway $10 \quad$ R28: Runway 28

N1: Nopember One N2: Nopember Two

N3 : Nopember Three N5: Nopember Five 
N6: Nopember Six N7: Nopember Seven

S1 : Siera One S2 : Siera Two

S3 : Siera Three

S4 : Siera Four dengan runway dan runway dengan wilayah approach dalam keadaan idle. Selain itu, harus melihat prioritas yang diberikan yaitu

S5 : Siera Five

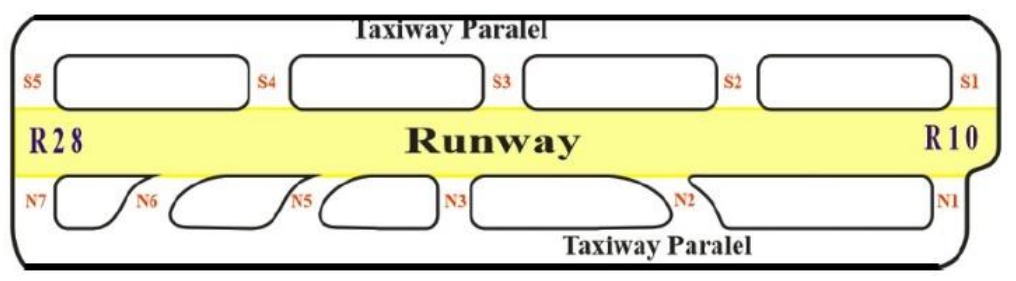

Gambar 1. Runway Bandara Internasional Juanda

Dari gambar 1, berikut ini disusun model petri net alur pergerakan pesawat menuju ke runway. mendahulukan pesawat yang akan landing atau pesawat yang akan take off berjalan menuju ke runway, yang dalam hal ini di

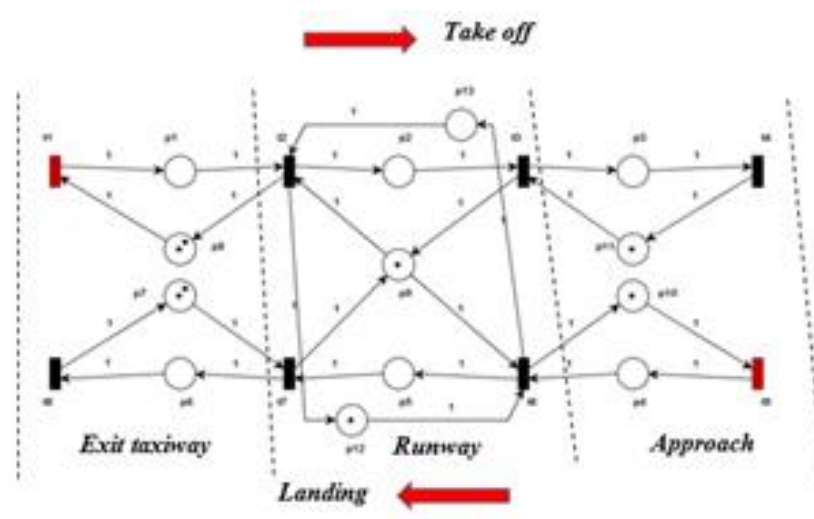

Gambar 2. Model petri net pergerakan pesawat di runway

$P$ merupakan himpunan berhingga place, $P=\left\{p_{1}, p_{2}, p_{3}, \cdots, p_{13}\right\}$ dan jumlah token yang terdapat pada masing-masing place $p_{1}, p_{2}, p_{3}, p_{4}, p_{5}, p_{6}$ menunjukan keberadaan atau posisi pesawat pada saat ke$k$, dan place $p_{7}, p_{8}, p_{9}, p_{10}, p_{11}$ menunjukan jalur yang dapat digunakan pesawat untuk melintas ke tempat atau posisi selanjutnya saat ke- $k$. Sedangkan $T=\left\{t_{1}, t_{2}, t_{3}, \cdots, t_{8}\right\}$ merupakan himpunan berhingga transisi, yang menunjukan pergerakan pesawat saat take offllanding di runway.

Untuk pergerakan pesawat, saat take off maupun landing harus menunggu jalur yang menghubungkan antara exit taxiway tandai dengan place $p_{12}$ dan $p_{13}$ pada gambar 2.

\section{B. Model Aljabar Max-Plus}

Dalam melakukan pemodelan aljabar max-plus pada model petri net gambar 2 dianalogikan terdapat 2 place yang menghubungkan transisi input dan transisi output, yaitu transisi $t_{1}$ dengan $t_{4}$ dan transisi $t_{5}$ dengan $t_{8}$. Place ini difungsikan sebagai penanda selang waktu antara pesawat yang keluar dari sistem dengan pesawat yang masuk ke dalam sistem. Dalam hal ini, jika ada $n$ pesawat pada saat ke- $k$ yang take off untuk pesawat yang akan 
take off berikutnya $(k+1)$ harus menunggu ke- $(k+1-n)$ yang meninggalkan bandara (keluar sistem) dalam selang waktu tertentu. Berikut ini diberikan ilustrasi posisi saat terjadinya pertemuan antara pesawat yang akan landing dan take off, lihat gambar 3.

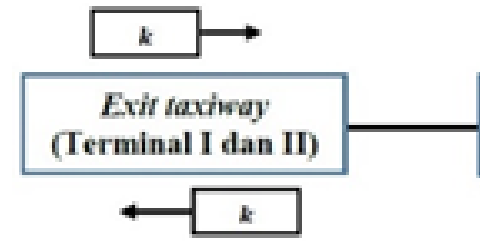

$a_{1}$ lama kedatangan pesawat dari luar sistem (apron) ke exit taxiway pada saat ke- $k$.

$a_{2}$ lama pesawat berhenti di exit taxiway pada saat ke- $k$.

$a_{3}$ lama pesawat selama di runway (take off) pada saat ke- $k$.

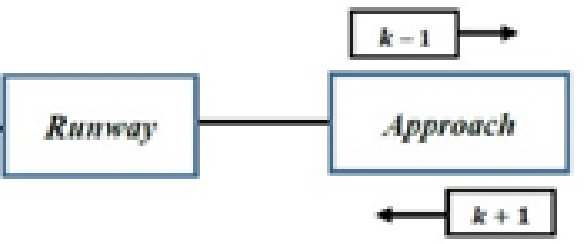

Gambar 3. Posisi terjadinya pertemuan pesawat saat take off dan landing yang berjalan berlawanan arah

Diberikan pendefinisian variabel yang menunjukan waktu dan variabel yang menunjukan lama waktu.

Variabel yang menunjukan waktu

$t_{1}(k)$ waktu kedatangan pesawat dari luar sistem (apron) ke exit taxiway pada saat ke- $k$.

$t_{2}(k)$ waktu pesawat take off dari exit taxiway (masuk ke runway) pada saat ke- $k$.

$t_{3}(k)$ waktu pesawat keluar dari runway pada saat ke- $k$.

$t_{4}(k)$ waktu pesawat keluar dari sistem (menuju bandara tujuan) pada saat ke$k$.

$t_{5}(k)$ waktu kedatangan pesawat dari luar sistem (bandara asal) ke approach (siap landing) pada saat ke- $k$.

$t_{6}(k)$ waktu pesawat landing dari approach (masuk ke runway) pada saat ke- $k$.

$t_{7}(k)$ waktu pesawat keluar dari runway pada saat ke- $k$.

$t_{8}(k)$ waktu pesawat keluar dari sistem (menuju ke apron) pada saat ke- $k$.

Variabel yang menunjukan lama waktu $a_{4}$ lama pesawat berhenti di approach pada saat ke- $k$.

$a_{5}$ lama kedatangan pesawat dari luar sistem (bandara asal) ke approach pada saat ke- $k$.

$a_{6}$ lama pesawat berhenti di approach (siap untuk landing) pada saat ke- $k$.

$a_{7}$ lama pesawat selama di runway (landing) pada saat ke- $k$.

$a_{8}$ lama pesawat berhenti di exit taxiway pada saat ke- $k$.

$b$ lama waktu tunggu pesawat setelah kedatangan pesawat dari arah berlawanan maupun yang searah.

Model aljabar max-plus untuk pergerakan pesawat saat take off dari exit taxiway menuju ke runway dan pergerakan pesawat saat landing dari posisi pesawat di approach (siap landing) menuju ke runway. Transisi $t_{1}$ merupakan transisi yang menunjukan kedatangan pesawat berikutnya $(k+1)$ dari apron (luar sistem) tiba di exit taxiway.

$$
\begin{aligned}
t_{1}(k+1)= & {\left[a_{1} \otimes t_{4}(k-2)\right] \oplus } \\
& {\left[b \otimes t_{2}(k-1)\right] \oplus }
\end{aligned}
$$




$$
\begin{aligned}
& {\left[b \otimes t_{8}(k-1)\right] \oplus[b \otimes} \\
& \left.t_{7}(k+1)\right] \text {. }
\end{aligned}
$$

Transisi $t_{2}$ merupakan transisi yang menandakan pergerakan pesawat take off yang berikutnya $(k+1)$ dari exit taxiway (masuk ke runway).

$$
\begin{aligned}
& t_{2}(k+1)=\left[a_{2} \otimes t_{1}(k+1)\right] \oplus[b \otimes \\
& \left.t_{7}(k+1)\right]
\end{aligned}
$$

Transisi $t_{3}$ merupakan transisi yang menandakan pesawat yang berikutnya $(k+1)$ keluar dari runway (take off).

$$
\begin{aligned}
& t_{3}(k+1)=\left[a_{3} \otimes t_{2}(k+1)\right] \oplus \\
& {\left[b \otimes t_{4}(k)\right] \oplus[b \otimes} \\
& \left.t_{6}(k+1)\right]
\end{aligned}
$$

Transisi $t_{4}$ merupakan transisi yang menandakan pesawat keluar dari sistem (menuju bandara tujuan) yang berikutnya ke$(k+1)$.

$t_{4}(k+1)=\left[a_{4} \otimes t_{3}(k+1)\right]$

Transisi $t_{5}$ merupakan transisi yang menunjukkan kedatangan pesawat berikutnya $(k+1)$ dari luar sistem (bandara asal) ke approach (siap landing).

$$
\begin{aligned}
t_{5}(k+1)= & {\left[a_{5} \otimes t_{8}(k-1)\right] \oplus } \\
& {\left[b \otimes t_{6}(k)\right] \oplus[b \otimes} \\
& t 4 k-1 \oplus[b \otimes t 3 k] \ldots
\end{aligned}
$$

Transisi $t_{6}$ merupakan transisi yang menandakan pergerakan pesawat landing yang berikutnya $(k+1)$ dari approach (masuk ke runway).

$$
\begin{aligned}
& t_{6}(k+1)=\left[a_{6} \otimes t_{5}(k+1)\right] \oplus[b \otimes \\
& t(k)]
\end{aligned}
$$

Transisi $t_{7}$ merupakan transisi yang menandakan pesawat yang berikutnya $(k+1)$ keluar dari runway (landing).

$t_{7}(k+1)=\left[a_{7} \otimes t_{6}(k+1)\right] \oplus$

$$
\left[b \otimes t_{8}(k-1)\right] \oplus[b \otimes
$$$$
\left.t_{2}(k)\right]
$$

Transisi $t_{8}$ merupakan transisi yang menandakan pesawat keluar dari sistem (menuju ke apron) yang berikutnya $(k+1)$.

$$
t_{8}(k+1)=\left[a_{8} \otimes t_{7}(k+1)\right]
$$

Dari (1), (2), (3), (4), (5), (6), (7), dan (8) dapat ditulis menjadi satu kesatuan dalam notasi matriks

$t(k+1)=\left[A_{0} \otimes t(k+1)\right] \oplus$ $\left[A_{1} \otimes t(k)\right] \oplus\left[A_{2} \otimes\right.$ $t k-1 \oplus A 3 \otimes t k-2$

dengan

$$
\begin{aligned}
& t(k+1)=\left[t_{1}(k+1) t_{2}(k+\right. \\
& 1 \cdots t 8(k+1)]^{\prime} \\
& t(k)=\left[\begin{array}{llll}
t_{1}(k) & t_{2}(k) & \cdots & t_{8}(k)
\end{array}\right]^{\prime} \\
& t(k-1)=\left[t_{1}(k-1) t_{2}(k-\right. \\
& 1 \cdots t 8(k-1)]^{\prime} \\
& t(k-2)=\left[t_{1}(k-2) t_{2}(k-\right. \\
& 2 \cdots t 8(k-2)]^{\prime}
\end{aligned}
$$

dan,

$A_{0}=\left[\begin{array}{cccccccc}\epsilon & \epsilon & \epsilon & \epsilon & \epsilon & \epsilon & b & \epsilon \\ a_{2} & \epsilon & \epsilon & \epsilon & \epsilon & \epsilon & b & \epsilon \\ \epsilon & a_{3} & \epsilon & \epsilon & \epsilon & b & \epsilon & \epsilon \\ \epsilon & \epsilon & a_{4} & \epsilon & \epsilon & \epsilon & \epsilon & \epsilon \\ \epsilon & \epsilon & \epsilon & \epsilon & \epsilon & \epsilon & \epsilon & \epsilon \\ \epsilon & \epsilon & \epsilon & \epsilon & a_{6} & \epsilon & \epsilon & \epsilon \\ \epsilon & \epsilon & \epsilon & \epsilon & \epsilon & a_{7} & \epsilon & \epsilon \\ \epsilon & \epsilon & \epsilon & \epsilon & \epsilon & \epsilon & a_{8} & \epsilon\end{array}\right]$

$A_{1}=\left[\begin{array}{llllllll}\epsilon & \epsilon & \epsilon & \epsilon & \epsilon & \epsilon & \epsilon & \epsilon \\ \epsilon & \epsilon & \epsilon & \epsilon & \epsilon & \epsilon & \epsilon & \epsilon \\ \epsilon & \epsilon & \epsilon & b & \epsilon & \epsilon & \epsilon & \epsilon \\ \epsilon & \epsilon & \epsilon & \epsilon & \epsilon & \epsilon & \epsilon & \epsilon \\ \epsilon & \epsilon & b & \epsilon & \epsilon & b & \epsilon & \epsilon \\ \epsilon & \epsilon & b & \epsilon & \epsilon & \epsilon & \epsilon & \epsilon \\ \epsilon & b & \epsilon & \epsilon & \epsilon & \epsilon & \epsilon & \epsilon \\ \epsilon & \epsilon & \epsilon & \epsilon & \epsilon & \epsilon & \epsilon & \epsilon\end{array}\right]$

$A_{2}=\left[\begin{array}{llllllll}\epsilon & b & \epsilon & \epsilon & \epsilon & \epsilon & \epsilon & b \\ \epsilon & \epsilon & \epsilon & \epsilon & \epsilon & \epsilon & \epsilon & \epsilon \\ \epsilon & \epsilon & \epsilon & \epsilon & \epsilon & \epsilon & \epsilon & \epsilon \\ \epsilon & \epsilon & \epsilon & \epsilon & \epsilon & \epsilon & \epsilon & \epsilon \\ \epsilon & \epsilon & \epsilon & b & \epsilon & \epsilon & \epsilon & a_{5} \\ \epsilon & \epsilon & \epsilon & \epsilon & \epsilon & \epsilon & \epsilon & \epsilon \\ \epsilon & \epsilon & \epsilon & \epsilon & \epsilon & \epsilon & \epsilon & b \\ \epsilon & \epsilon & \epsilon & \epsilon & \epsilon & \epsilon & \epsilon & \epsilon\end{array}\right]$ 


$$
A_{3}=\left[\begin{array}{llllllll}
\epsilon & \epsilon & \epsilon & a_{4} & \epsilon & \epsilon & \epsilon & \epsilon \\
\epsilon & \epsilon & \epsilon & \epsilon & \epsilon & \epsilon & \epsilon & \epsilon \\
\epsilon & \epsilon & \epsilon & \epsilon & \epsilon & \epsilon & \epsilon & \epsilon \\
\epsilon & \epsilon & \epsilon & \epsilon & \epsilon & \epsilon & \epsilon & \epsilon \\
\epsilon & \epsilon & \epsilon & \epsilon & \epsilon & \epsilon & \epsilon & \epsilon \\
\epsilon & \epsilon & \epsilon & \epsilon & \epsilon & \epsilon & \epsilon & \epsilon \\
\epsilon & \epsilon & \epsilon & \epsilon & \epsilon & \epsilon & \epsilon & \epsilon \\
\epsilon & \epsilon & \epsilon & \epsilon & \epsilon & \epsilon & \epsilon & \epsilon
\end{array}\right]
$$

Selanjutnya diinputkan nilai parameter waktu tempuh yang diperlukan waktu pesawat untuk take off, yaitu $a_{3}=1$ menit dan waktu yang diperlukan pesawat untuk landing, yaitu $a_{7}=3$ menit. Sementara nilai parameter yang lain adalah 0 menit, artinya pesawat berjalan secara periodik tanpa menunggu pesawat sebelum atau selanjutnya. Kemudian persamaan (9) dikontruksi menjadi

$$
\begin{aligned}
t(k+1)= & {\left[\left(A_{0}^{*} \otimes A_{1}\right) \otimes t(k)\right] \oplus } \\
& {\left[\left(A_{0}^{*} \otimes A_{2}\right) \otimes t(k-1)\right] \oplus } \\
& {\left[\left(A_{0}^{*} \otimes A_{3}\right) \otimes t(k-2)\right] \ldots .(10) }
\end{aligned}
$$

dengan

$$
\begin{aligned}
A_{0}^{*} \otimes A_{1} & =\left[\begin{array}{llllllll}
\epsilon & 0 & 3 & \epsilon & \epsilon & 3 & \epsilon & \epsilon \\
\epsilon & 0 & 3 & \epsilon & \epsilon & 3 & \epsilon & \epsilon \\
\epsilon & 1 & 4 & 0 & \epsilon & 4 & \epsilon & \epsilon \\
\epsilon & 1 & 4 & 0 & \epsilon & 4 & \epsilon & \epsilon \\
\epsilon & \epsilon & 0 & \epsilon & \epsilon & 0 & \epsilon & \epsilon \\
\epsilon & \epsilon & 0 & \epsilon & \epsilon & 0 & \epsilon & \epsilon \\
\epsilon & 0 & 3 & \epsilon & \epsilon & 3 & \epsilon & \epsilon \\
\epsilon & 0 & 3 & \epsilon & \epsilon & 3 & \epsilon & \epsilon
\end{array}\right] \\
A_{0}^{*} \otimes A_{2} & =\left[\begin{array}{llllllll}
\epsilon & 0 & \epsilon & 3 & \epsilon & \epsilon & \epsilon & 3 \\
\epsilon & 0 & \epsilon & 3 & \epsilon & \epsilon & \epsilon & 3 \\
\epsilon & 1 & \epsilon & 4 & \epsilon & \epsilon & \epsilon & 4 \\
\epsilon & 1 & \epsilon & 4 & \epsilon & \epsilon & \epsilon & 4 \\
\epsilon & \epsilon & \epsilon & 0 & \epsilon & \epsilon & \epsilon & 0 \\
\epsilon & \epsilon & \epsilon & 0 & \epsilon & \epsilon & \epsilon & 0 \\
\epsilon & \epsilon & \epsilon & 3 & \epsilon & \epsilon & \epsilon & 3 \\
\epsilon & \epsilon & \epsilon & 3 & \epsilon & \epsilon & \epsilon & 3
\end{array}\right] \\
A_{0}^{*} \otimes A_{3} & =\left[\begin{array}{llllllll}
\epsilon & \epsilon & \epsilon & 0 & \epsilon & \epsilon & \epsilon & \epsilon \\
\epsilon & \epsilon & \epsilon & 0 & \epsilon & \epsilon & \epsilon & \epsilon \\
\epsilon & \epsilon & \epsilon & 1 & \epsilon & \epsilon & \epsilon & \epsilon \\
\epsilon & \epsilon & \epsilon & 1 & \epsilon & \epsilon & \epsilon & \epsilon \\
\epsilon & \epsilon & \epsilon & \epsilon & \epsilon & \epsilon & \epsilon & \epsilon \\
\epsilon & \epsilon & \epsilon & \epsilon & \epsilon & \epsilon & \epsilon & \epsilon \\
\epsilon & \epsilon & \epsilon & \epsilon & \epsilon & \epsilon & \epsilon & \epsilon \\
\epsilon & \epsilon & \epsilon & \epsilon & \epsilon & \epsilon & \epsilon & \epsilon
\end{array}\right]
\end{aligned}
$$

Persamaan (10) ditransformasikan ke dalam bentuk persamaan relasi rekurensi orde-1 yaitu

$\tilde{t}(k+1)=\tilde{A}(k) \otimes \tilde{t}(k)$

dengan

$\tilde{A}=\left[\begin{array}{ccc}A_{0}^{*} \otimes A_{1} & A_{0}^{*} \otimes A_{2} & A_{0}^{*} \otimes A_{3} \\ E & \epsilon & \epsilon \\ \epsilon & E & \epsilon\end{array}\right]$

dan

$\tilde{t}(k)=\left[t^{\prime}(k), t^{\prime}(k-1), t^{\prime}(k-2)\right]$

Persamaan (11) merupakan model aljabar max-plus dari permasalahan ini. Dari hasil simulasi, diperoleh bahwa nilai eigen $\lambda=4$ menit. Angka ini menunjukan bahwa diperlukan waktu 4 menit bagi pesawat untuk berjalan searah pada siklus selanjutnya dari masing-masing posisi pesawat (exit taxiway dan approach) saat akan masuk ke runway. Berikut ini hasil simulasi kedatangan dan keberangkatan pesawat untuk 60 menit pertama, dapat dilihat bahwa pada selang waktu tersebut dapat digunakan untuk memberangkatkan 15 pesawat yang take off dan 15 pesawat yang landing (lihat gambar 4).

\section{KESIMPULAN}

Kapsitas runway Bandara Internasional Juanda yang diperoleh dari keperiodikan minimum pada aljabar max-plus adalah 30 pesawat (take offllanding) per jam.

\section{DAFTAR PUSTAKA}

Angkasa Pura Airport. (2015). Aeodrome Manual. Surabaya: PT Angkasa pura I (Persero) Bandara Internasional Juanda.

Cassandras, C.G. (1993). Discrete Event Systems: Modeling and Performance 
Analysis. Aksen Associates Incorporated Publishers. Boston.

Heidergott, B., Olsder, G.J., \& Woude, J. V. (2006). Max Plus at Work, Modeling and analysis of Synchronized System: A Course on MaxPlus Algebra and Its Appli-cations. United Kingdom: Prince-tton University Press.

Moody, John O dan Antsaklis, P. J. (1998).

Supervisory Control of Discrete Event Systems Using Petri Nets. Notre Dame: University of Notre Dame.

Panguriseng, Zadly A. (2010). Penentuan Jumlah Exit Taxiway Berdasarkan Variasi Jenis Pesawat dan Kerapatan Jadwal Penerbangan pada
Bandara Ianternasional Juanda. Surabaya: Institut Teknologi Sepuluh Nopember.

Subiono. (2015). Aljabar Min-Max plus dan Terapannya. Surabaya: Institut Teknologi Sepuluh Nopember.

Utomo, Tri. (2015). Struktur Hierarkis Jalur Kereta Api Semi Double Track Menggunakan Petri Net dan Al-jabar Max-Plus. Surabaya: Institut Teknologi Sepuluh November.

Zhou, M.C dan Hruz, B. (2007). Modeling and Control of Discrete-Event Dynamic System with Petri Nets and Other Tool. Springer Publisher. London. 
| Jurnal PRIMATIKA, Volume 8, Nomor 2, Desember 2019

110 Menghitung kapasitas runway menggunakan petri net dan aljabar max-plus Petrus Fendiyanto 